\title{
Height patterning of nanostructured surfaces with a focused helium ion beam: a precise and gentle non-sputtering method
}

Tavares, L.; Chiriaev, S.; Adashkevich, V; Taboryski, Rafael J.; Rubahn, H.-G.

Published in:

Nanotechnology

Link to article, DOI:

$10.1088 / 1361-6528 / a b 6679$

Publication date:

2020

Document Version

Peer reviewed version

Link back to DTU Orbit

Citation (APA):

Tavares, L., Chiriaev, S., Adashkevich, V., Taboryski, R. J., \& Rubahn, H-G. (2020). Height patterning of nanostructured surfaces with a focused helium ion beam: a precise and gentle non-sputtering method. Nanotechnology, 31(14), [145303]. https://doi.org/10.1088/1361-6528/ab6679

\section{General rights}

Copyright and moral rights for the publications made accessible in the public portal are retained by the authors and/or other copyright owners and it is a condition of accessing publications that users recognise and abide by the legal requirements associated with these rights.

- Users may download and print one copy of any publication from the public portal for the purpose of private study or research.

- You may not further distribute the material or use it for any profit-making activity or commercial gain

- You may freely distribute the URL identifying the publication in the public portal 


\title{
Height patterning of nanostructured surfaces with a focused helium ion beam: a precise and gentle non-sputtering method
}

\author{
L. Tavares ${ }^{1}$, S. Chiriaev ${ }^{1}$, V. Adashkevich ${ }^{2}$, R. Taboryski ${ }^{3}$, and H.-G. Rubahn ${ }^{1}$ \\ ${ }^{1}$ Mads Clausen Institute, NanoSYD, University of Southern Denmark, Sønderborg, 6400, Denmark \\ ${ }^{2}$ Mads Clausen Institute, Centre for Industrial Electronics, University of Southern Denmark, \\ Sønderborg, 6400, Denmark \\ ${ }^{3}$ National Centre for Nano Fabrication and Characterization, Technical University of Denmark, \\ Kongens Lyngby, 2800, Denmark \\ E-mail: tavares@mci.sdu.dk
}

\begin{abstract}
This work presents a new technique for surface patterning with focused ion beams. The technique is based on chemical decomposition in the bulk of a polymer substrate with negligible surface sputtering effects. By using a focused helium ion beam, generated in a helium ion microscope, we show that the surface height of polymethyl methacrylate substrates can be patterned with nanometer depth precision, while preserving the essential features of the nanostructures prefabricated on this surface. The key factors that control this patterning process are discussed.
\end{abstract}

Keywords: Helium focused ion beam, surface height nanopatterning, direct patterning

\section{Introduction}

Focused ion beams (FIBs) of light atoms, such as helium $\left(\mathrm{He}^{+}\right)$and neon $\left(\mathrm{Ne}^{+}\right)$, generated by a gas field ion source (GFIS), have opened a new route to direct (maskless) surface nanopatterning characterized by a superior lateral resolution combined with a high precision of depth control [1,2]. Two major methods have been used until present for surface patterning with FIBs, namely ion-beam milling (sputtering of the surface layers) and ion-beam assisted chemical vapor deposition [2].

FIBs modify both the surface and the bulk of materials in many ways, which are based on a variety of interactions of the ion beams with materials, including formation of radiation-induced damage and implantation of impurities [3]. In this work we demonstrate that, in addition to the existing methods, a helium FIB is capable of patterning surface morphology by means of bulk processes, leaving prefabricated surface structures essentially intact. 
The suggested patterning technique is based on peculiarities of the energy losses by light ions in polymer materials and on the resulting chemical decomposition $[3,4,5]$. When light energetic ions interact with solids, a dominant energy loss mechanism results from the interaction with target electrons, which corresponds to ionization damage almost over the entire ion path in the solid. Another important factor is the localization of the maximum concentration of implanted ions and of radiation damage caused by elastic collisions of the ions with target atoms at relatively large depths below the surface. These factors result in a relatively low level of surface damage and a low sputtering rate based on the elastic collisions. On the other hand, the ionization losses are high at the surface. Helium ion microscopy (HIM [1]) takes advantage from such a distribution of the energy losses, because the rate of image artefacts caused by sputtering is low and the number of secondary electrons generated near the surface is high, which is a prerequisite for high-quality surface imaging.

In the context of this work, the capability of ion beams to chemically decompose polymer materials via both electronic and nuclear energy losses is essential (see e.g. Ref. 4 and references therein). Polymethyl methacrylate (PMMA) is especially interesting in this respect. It has a very broad range of industrial and scientific applications and has been used for a long time in microelectronics and microfabrication as a positive resist for X-ray, deep UV [6], electron and ion-beam lithography [7]. Extensive research (e.g. ref. $[4,5,7,8,9,10,11]$ ) has shown that PMMA is highly sensitive to ion irradiation and that the ion bombardment can result in material volume shrinkage induced by a range of chemical and structural transformations in the polymer bulk. In this work, we utilize FIB-induced volume shrinkage to manipulate the surface height, while the prevailing part of the nuclear energy losses is "hidden" in the substrate bulk to minimize the surface sputtering effects. To demonstrate the preservation of the surface features we used two model systems: 1) PMMA films deposited on silicon substrates and 2) bulk PMMA wafers with prefabricated nanopillars.

\section{Experimental procedures}

Both model sample systems contained thin metal films on their surface. The deposition of these films was done for two reasons: 1) to avoid any surface charging effects that could disturb the patterning process and 2) because the height patterning of thin metal films and their structures is interesting itself from the point of view of a very broad range of thin film applications. The choice of the metal films for our model systems was determined by general requirements that the films must be as thin as possible to minimize the amount of the nuclear collision events in their volume, but nevertheless capable of providing the electrical charge removal during the irradiation. The PMMA layers in the first model system were deposited on the surface of blank silicon wafers and covered by a $15 \mathrm{~nm}$ thick platinum/palladium $\left(\mathrm{Pt}_{60} \mathrm{Pd}_{40}\right)$ alloy film. 
In order to investigate effects of PMMA film thickness and of localization of the ion energy losses within the multilayer structure we used thin $(200 \mathrm{~nm})$ and thick $(770 \mathrm{~nm})$ PMMA layers. Computer simulations performed with SRIM (Stopping and Range of Ions in Matter) software showed that, for the energy of $\mathrm{He}^{+}$ions used in this work, a significant part of the electronic energy losses and the nuclear collision events is localized in the underlying silicon substrate, in the samples with $200 \mathrm{~nm}$ PMMA layer (figure S1 in the supplementary material). In the samples with $770 \mathrm{~nm}$ PMMA layer, the electronic energy losses and the nuclear collision events are localized mainly in the polymer bulk (figure $\mathrm{S} 2$ in the supplementary material).

The PMMA layers were deposited on the silicon wafers by spin-coating technique in an RRT Lanz EBS 11 spin-coater, and according to the parameters presented in Table S1 of the supplementary material. After the deposition all the samples were annealed at $200^{\circ} \mathrm{C}$ for $90 \mathrm{~s}$ in order to remove solvent residuals. The thicknesses of the PMMA films were measured by ellipsometry. The $\mathrm{Pt}_{60} \mathrm{Pd}_{40}$ films were deposited on the surface of the PMMA layers by DC sputtering in a Cressington $208 \mathrm{HR}$ sputter.

The bulk PMMA samples were $2 \mathrm{~mm}$ thick wafers fabricated by an injection moulding method. On the surface of these wafers, dense arrays of hexagonally packed nanopillars were fabricated. The diameters of the pillars were around $55 \mathrm{~nm}$, and the pillar height to diameter aspect ratio was approximately one. The pitch size in the pattern was of about $73 \mathrm{~nm}$. After fabrication, the nanostructured PMMA surface was coated with an $8 \mathrm{~nm}$ thick tungsten (W) film. The SRIM simulations show that, similarly to the $770 \mathrm{~nm}$ PMMA film, the electronic energy losses and the nuclear collision events occur mainly within the PMMA bulk (see figure S3 in the supplementary material). The method and procedures for fabrication of these samples are described in Ref. 12 and references therein. Preliminary investigations demonstrated that both $\mathrm{Pt}_{60} \mathrm{Pd}_{40}$ and $\mathrm{W}$ thin films deposited on the surface of our model samples provided the removal of electrical charge from the sample surface.

The irradiation of the samples with $\mathrm{He}^{+}$ions was done in a Zeiss Orion NanoFab Helium Ion Microscope at a landing energy of $25 \mathrm{keV}$. Two types of the irradiation patterns were applied. Arrays of $10 \times 10 \mu \mathrm{m}^{2}$ irradiated squares (figure 1(a)) were used for measurements of surface height dependence on the irradiation dose. The irradiation was done with doses in the range between $4 \times 10^{13} \mathrm{~cm}^{-2}$ and $5 \times 10^{15} \mathrm{~cm}^{-2}$. The beam current was kept at a value of around $1.7 \mathrm{pA}$. A beam dwell time of $2 \mu \mathrm{s}$ was used for all the irradiations. The distance between the edges of squares was $10 \mu \mathrm{m}$ to avoid possible interactions between the irradiated areas, such as overlapping originating from transverse ion straggle. Both the radiated and non-irradiated regions of the samples were characterized by atomic force microscopy (AFM) and by HIM. 
To demonstrate the capability of forming complex surface morphologies, a sequence of the ion irradiations has been done in overlapping sample areas, as shown in figure 1(b). The measurements of the surface height were performed with an AFM in tapping mode.
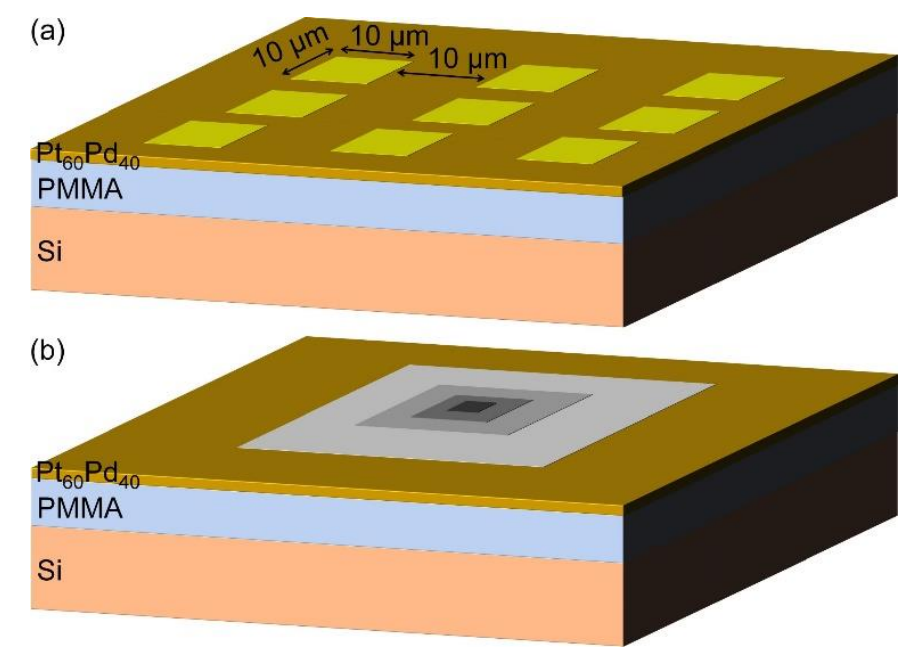

Figure 1. (a) The array of squares irradiated with different doses of $\mathrm{He}^{+}$ions. (b) The pattern of overlapping irradiated squares. The accumulated irradiation dose is changing from $2.6 \times 10^{13} \mathrm{~cm}^{-2}$ (for the largest square) to $3.1 \times 10^{15} \mathrm{~cm}^{-2}$ (for the smallest square).

\section{Results and discussion}

Figure 2 shows an AFM image and the corresponding depth profile of the surface pattern generated in a $\mathrm{Pt}_{40} \mathrm{Pd}_{60} / \mathrm{PMMA} \mathrm{Si}$ sample by a sequence of $\mathrm{He}^{+}$ion irradiations illustrated in figure 1(b). It is observed that such irradiations result in the formation of concave, step-pyramid-shaped surface depressions. We depict the value of the surface depressions in terms of reduction in the surface height, for which the baseline height corresponds to the non-irradiated area. As it is seen in figure 2 , the reduction in the surface height increases with the accumulated irradiation dose, which resulted in the formation of the pyramid-like indent. 

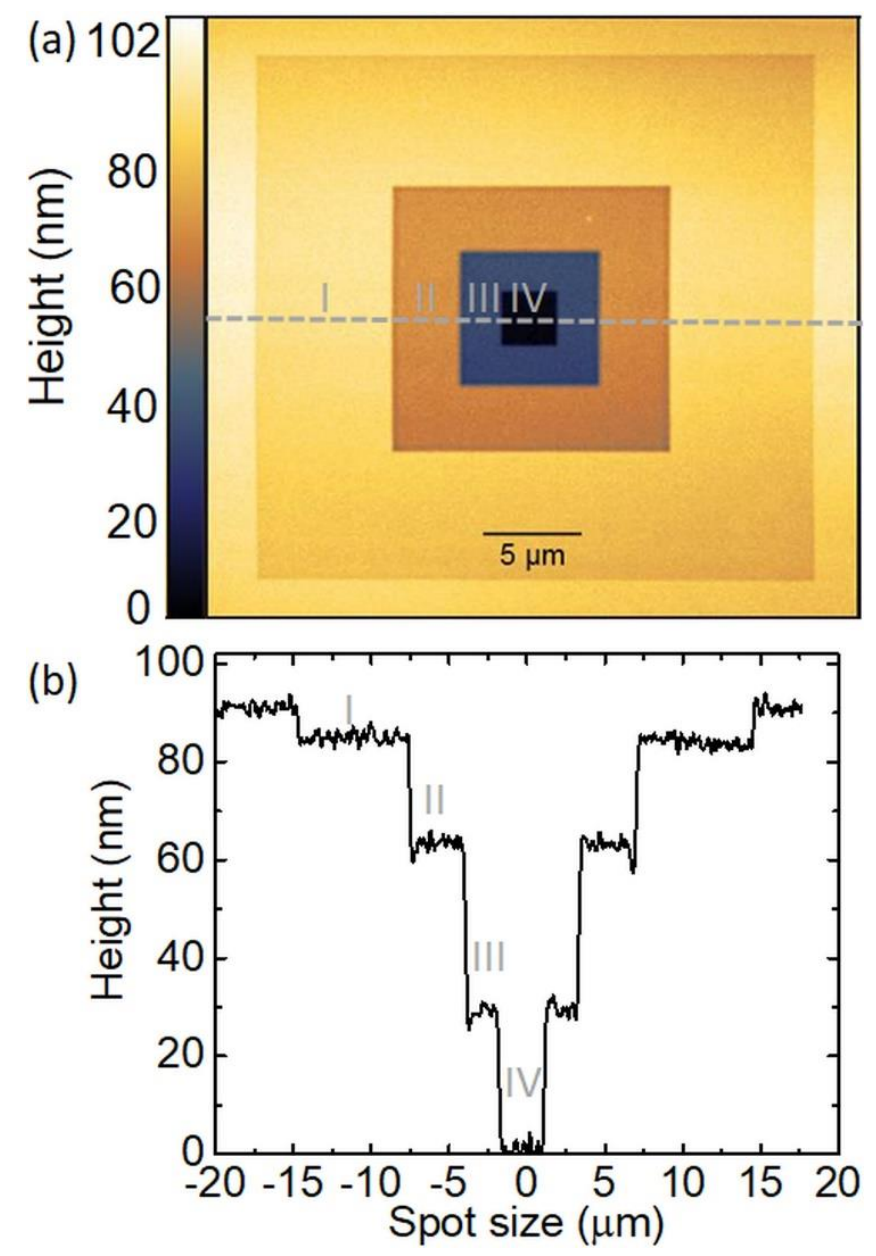

Figure 2. AFM image (a) and the corresponding depth profile (b) of the surface structure generated by a sequence $\mathrm{He}^{+}$irradiations into the $\mathrm{Pt}_{40} \mathrm{Pd} 60 / \mathrm{PMMA} / \mathrm{Si}$ sample. The thickness of PMMA layer is $200 \mathrm{~nm}$, and the thickness of $\mathrm{Pt}_{60} \mathrm{Pd}_{40}$ thin film is $15 \mathrm{~nm}$. The area was irradiated with the total dose in region I: $\mathbf{2 . 6} \times \mathbf{1 0}^{\mathbf{1 3}} \mathrm{cm}^{-2}$, in region II: $\mathbf{1 . 3} \times \mathbf{1 0}^{\mathbf{1 4}} \mathrm{cm}^{2}$, in region III: $\mathbf{5 . 4} \times \mathbf{1 0} \mathbf{1 0}^{-2}$ and in region IV: $\mathbf{3 . 1} \times \mathbf{1 0}^{15} \mathrm{~cm}^{-2}$. The dashed line in (a) indicates the place of the depth profile shown in (b).

For the irradiation patterns illustrated in figure 1(a), the achieved depth is plotted as a function of irradiation dose for two thicknesses of the PMMA layer (figure 3). Both curves are characterized by a relatively high rate of depth increase at low doses, followed by a saturation effect. Also, for the thick PMMA layer, the initial rate is larger and the saturation is less pronounced. 


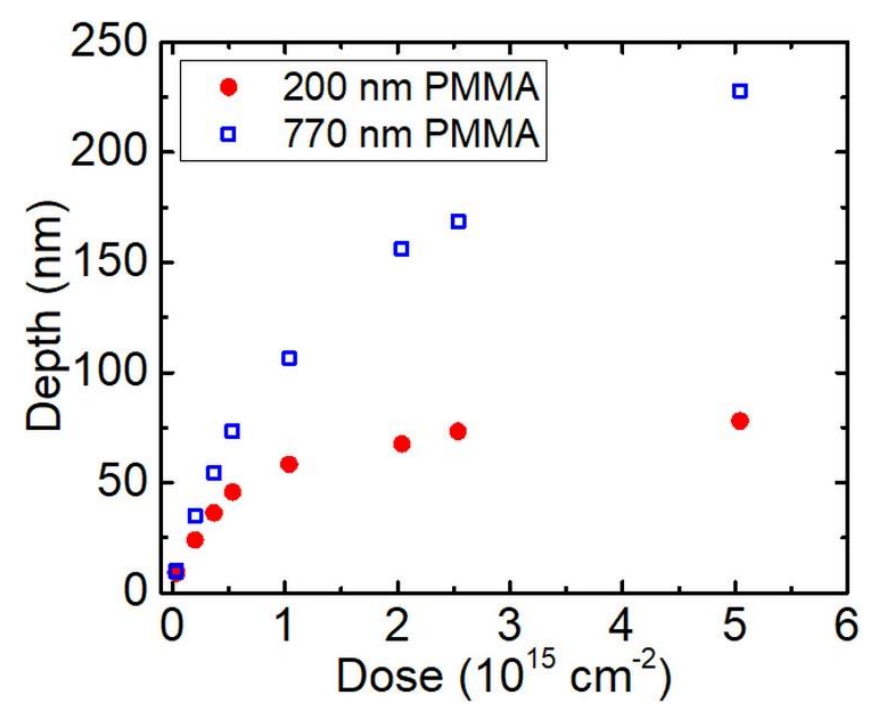

Figure 3. Dose dependence of the irradiation induced depth for $15 \mathrm{~nm} \mathrm{Pt} 60 \mathrm{Pd}_{40} / 200 \mathrm{~nm}$ PMMA and 15 nm Pt60 $\mathrm{Pd}_{40} / 770$ nm PMMA samples. The samples were irradiated with a $25 \mathrm{keV} \mathrm{He}^{+}$FIB.

These dependencies and the difference between the results for the samples with thin and thick PMMA layers can be well explained by the processes induced by $\mathrm{He}^{+} \mathrm{FIB}$ in the bulk of the PMMA layers and by the ion energy losses profiles within the layered structures.

PMMA is a hydrogenated, thermoplastic polymer that has a non-crosslinked amorphous structure [13]. Chemical changes and structural transformation produced in PMMA by ion irradiation have been subjects of long-term research $[3,4,5,7,8,9,10,11]$. The results show that the ion irradiation causes shrinkage and an increase in density of the irradiated PMMA material $[9,11,14,15,16]$. These phenomena are attributed to a sequence of processes that occur under irradiation. At low irradiation doses, the process of polymer-chain scission dominates. This results in the formation of low-atomic-weight, volatile molecules that diffuse to the surface and desorb from the polymer. Cross-linking and material compacting processes dominate at high irradiation doses [8], and both the material loss and material compacting contribute to the volume shrinkage. At very high doses, a sequence of structural rearrangements results in the formation of a compact carbon-rich material, which is structurally and chemically very different from the pristine PMMA [11], and for which the shrinkage capacity has essentially vanished. This material factor substantially limits the total capacity of the layered systems to shrink. The geometrical factors important for understanding the above dose dependencies include the thickness of the PMMA layer and the localization of the ion energy losses with respect to the PMMA layer. The overall reduction in the surface height depends on the subsurface amount of PMMA volume involved in the shrinking process. Therefore, the thickness of the PMMA layer gives an upper limit for the 
surface height reduction. The importance of the energy losses localization can be illustrated with the energy losses depth profiles simulated with SRIM and presented in figures S1, S2, and S3 in the supplementary material.

In the case of the thin PMMA layer (figure S1 in the supplementary material), a significant part of the electronic and nuclear energy losses occurs below the PMMA layer. In contrast, in the case of the thick PMMA layer, the energy losses occur mainly in the PMMA bulk (figure S2 in the supplementary material). Therefore, we attribute the lower surface-height reduction rate, in the case of the thinner PMMA layer, to a significantly smaller volume of PMMA material involved in the shrinkage process. The decrease in the shrinkage rate with increasing irradiation dose can be explained by the depletion of remaining material shrinkage capacity in the irradiated PMMA volume.

The HIM images presented in figure 4 show the surface morphology before and after irradiation of the samples with different prefabricated surface structures. We found that the irradiation of the $\mathrm{Pt}_{40} \mathrm{Pd}_{60} / \mathrm{PMMA} / \mathrm{Si}$ samples results in the formation of a network of cracks in the $\mathrm{Pt}_{40} \mathrm{Pd}_{60}$ film, as seen in the lower half of figure $4(\mathrm{a})$. Nevertheless, the $\mathrm{Pt}_{40} \mathrm{Pd}_{60}$ film remained electrically conductive: we have not observed any charging effects in the HIM images for the entire irradiation dose range used in this study. All the irradiations and imaging were performed without any aid for charge compensation available at the Orion NanoFab instrument.
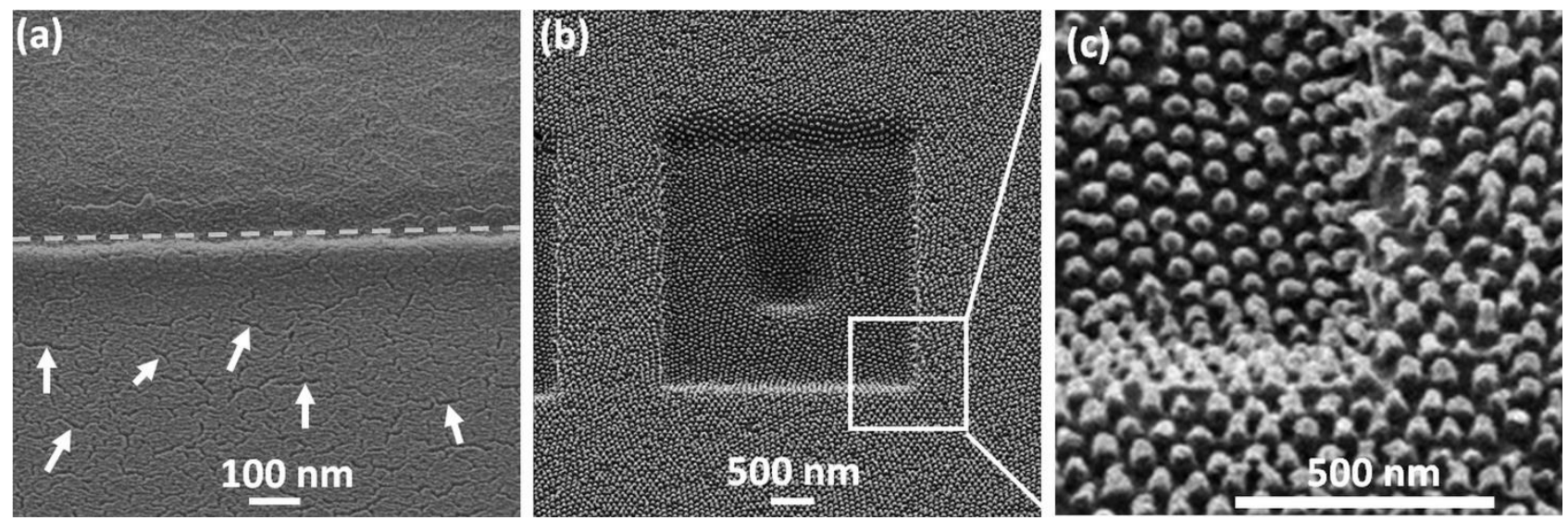

Figure 4. HIM images of (a) $15 \mathrm{~nm} \mathrm{Pt}_{60} \mathrm{Pd}_{40} / 200 \mathrm{~nm}$ PMMA layered structure irradiated with $\mathrm{He}^{+}$ions to a dose of $\mathbf{2 . 5} \times \mathbf{1 0}^{\mathbf{1 5}} \mathrm{cm}^{-2} ;(\mathrm{b})$ and (c) of the bulk PMMA wafer with the nanopillar array on the surface. The irradiation doses for the large and small square regions are

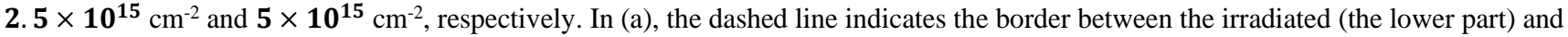
non-irradiated (the upper part) regions, and the arrows indicate some of the cracks.

The capability of the suggested patterning technique to preserve the geometry of prefabricated surface nanostructures is illustrated in figures 4(b) and 4(c), which show a pyramid-like nano-indent fabricated on the surface of the prepatterned sample, 
in a way like that of forming the pyramid-like indents in the first model samples. An additional and interesting outcome of this experiment is the change in orientation of the nanopillars, from perpendicular to inclined with respect to the base surface, within the border between the irradiated and non-irradiated areas (figure 4(b)-(c)) and the border between the areas irradiated with different doses (figure 4(b)). This provides an additional degree of freedom for spatial rearrangement of prefabricated nanostructures.

An important aspect of this patterning method is the necessity of providing a path for the volatile decomposition products to leave the sample. Numerous studies showed that, in a situation where such a path is not available or not efficient, accumulation of the volatile products in the bulk and at the surface can result in material swelling [9] or even in heavy surface damage, such as blistering and delamination [17]. Neither swelling nor blistering have been observed in our samples, and we explain this difference in the results by a combination of several factors. The first is a lower amount of volatile decomposition products generated per ion by our $25 \mathrm{keV} \mathrm{He}{ }^{+}$FIB. In the previous studies where swelling and blistering were observed, the irradiations with $\mathrm{He}^{+}$ions were performed at much higher energies (in an MeV range) into thick PMMA samples. Therefore, much larger polymer volumes were irradiated and much larger amounts of the decomposition products per unit area were generated. The second factor is a much larger depth of the radiation damage distributions, and therefore, a much longer path for the decomposition products to diffuse to the sample surface at the high energy irradiations. As it was demonstrated in Ref. 9, the transition from the swelled to the shrank state, due to the out-diffusion of the decomposition products, can take several days at room temperature after irradiation of PMMA with $\mathrm{He}^{+}$ions with energies in the MeV range.

Finally, any film on the surface of the PMMA material, for which the permeability of the decomposition products is smaller than that of PMMA, retards the decomposition products release and can result in film blistering and delamination. We explain the fact that neither of these effects were observed in our samples by the small thickness of the used metal films and by availability, or development during the irradiation, of pathways for "easy" permeation of the decomposition products. Obvious pathways for an easy release of the decomposition products are the cracks observed in the thin metal film.

\section{Conclusions}

In conclusion we emphasize that the main purpose of this work was demonstration of a novel fabrication method based on irradiation with helium ion beams, which modifies the surface height of metal-coated polymeric material while preserving its morphological features, and to a certain extent its physical properties. We have shown that the surface height of these structures 
can be controlled with high precision by the irradiation dose and by the geometry of the layered structures. Our further work on this subject is focused on detailed studies of advantages and limitations for this technique in relation to an extended range of the prefabricated surface nanostructures, ion beam energy effects, and on possible applications of this technique in the fabrication of microfluidic and optical devices.

\section{Supplementary material}

1. Additional SRIM simulations. Figure $\mathrm{S} 1$ shows the simulations for $15 \mathrm{~nm} \mathrm{Pt}_{60} \mathrm{Pd}_{40} / 200 \mathrm{~nm} \mathrm{PMMA}$, figure $\mathrm{S} 2$ shows the simulations for $15 \mathrm{~nm} \mathrm{Pt}_{60} \mathrm{Pd}_{40} / 770 \mathrm{~nm}$ PMMA, and figure $\mathrm{S} 3$ shows the simulations for $8 \mathrm{~nm} \mathrm{~W} / 2 \mathrm{~mm}$ PMMA. All simulations were done for $25 \mathrm{keV} \mathrm{He}{ }^{+}$irradiation.

2. The Table S1 shows the spin-coating procedures for deposition of PMMA layers for the first model sample.
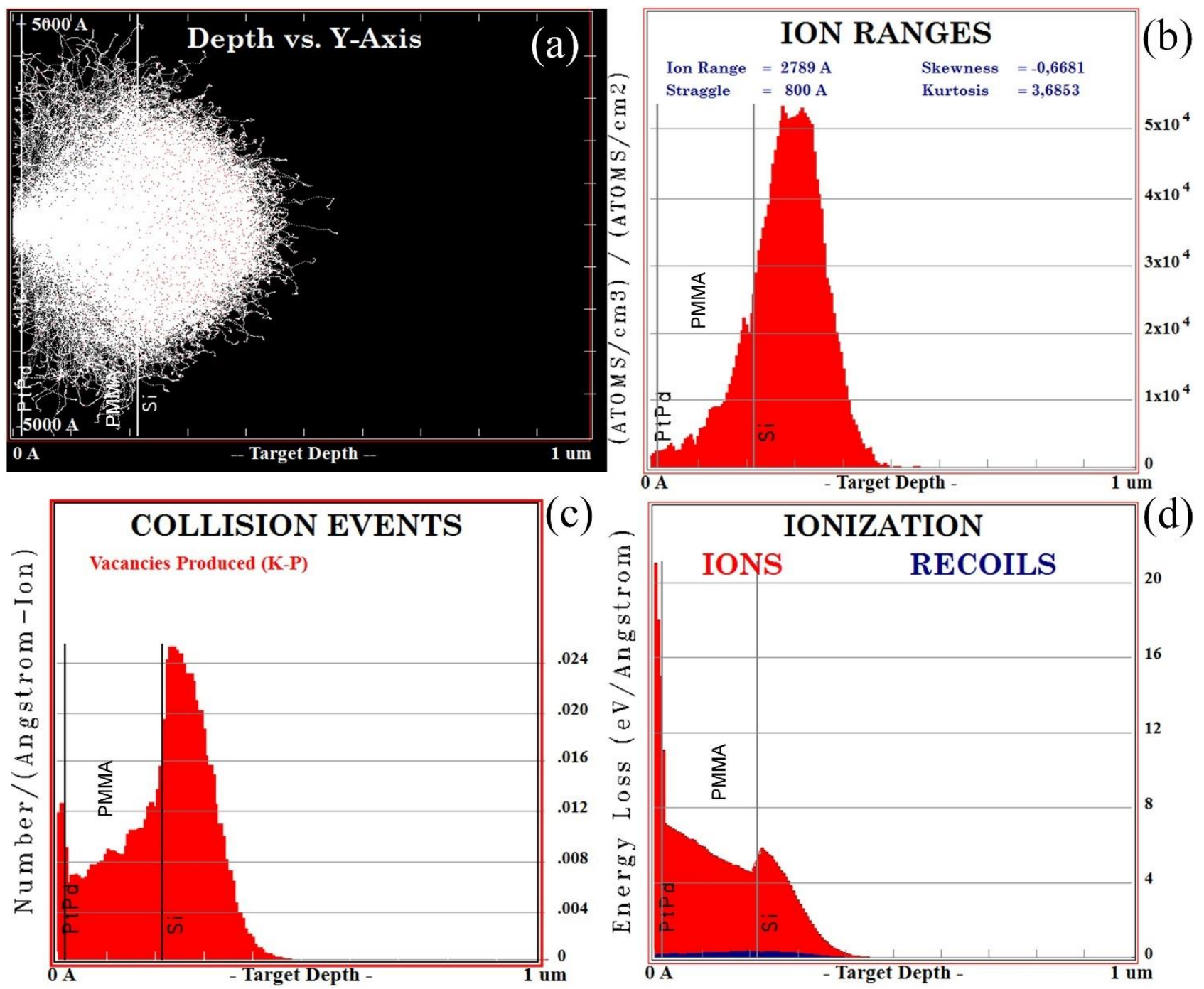
Figure S1. SRIM simulations for the samples composed of $15 \mathrm{~nm} \mathrm{Pt}{ }_{60} \mathrm{Pd}_{40} / 200 \mathrm{~nm}$ PMMA on silicon substrate and irradiated with $25 \mathrm{keV}$ $\mathrm{He}^{+}$. Simulations of collision (a), ion ranges (b), collisions events (c), and ionization (d).
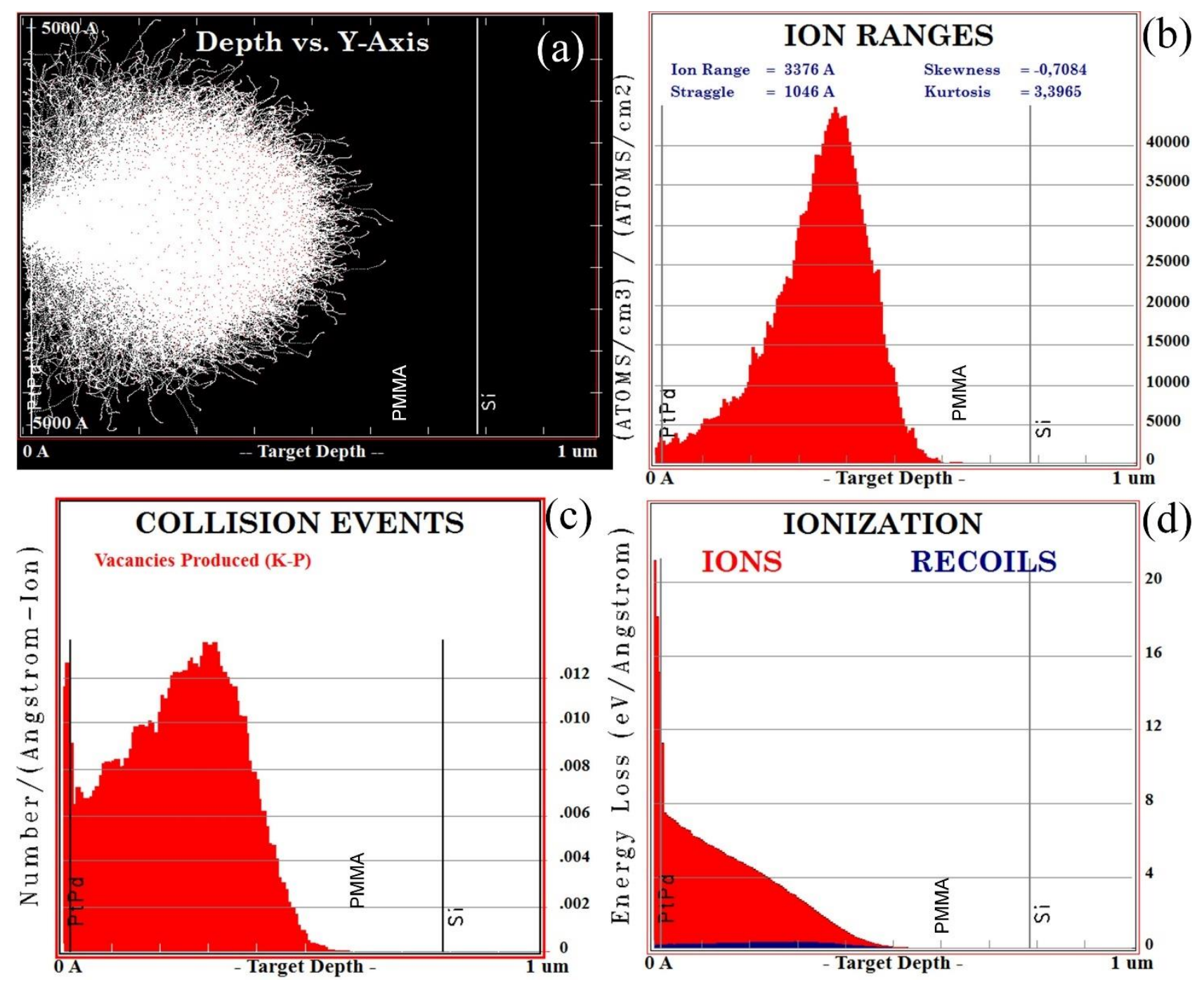

Figure S2. SRIM simulations for the samples composed of $15 \mathrm{~nm} \mathrm{Pt} 60 \mathrm{Pd}_{40} / 770 \mathrm{~nm}$ PMMA on silicon substrate and irradiated with $25 \mathrm{keV}$ $\mathrm{He}^{+}$. Simulations of collision (a), ion ranges (b), collisions events (c), and ionization (d). 

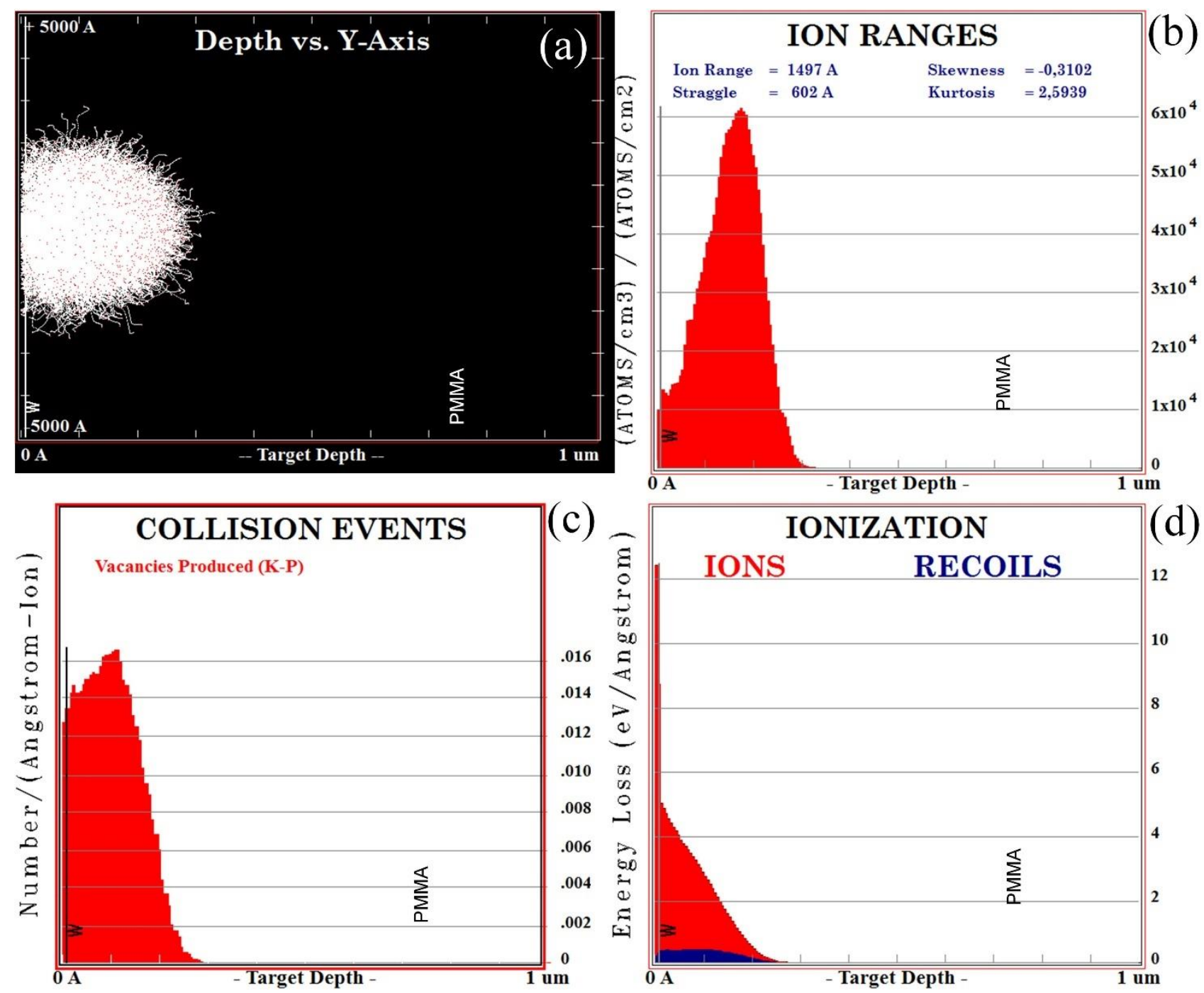

Figure S3. SRIM simulations for the samples composed of $8 \mathrm{~nm} \mathrm{~W} / 2 \mathrm{~mm}$ PMMA wafer irradiated with $25 \mathrm{keV} \mathrm{He}^{+}$. Simulations of collision (a), ion ranges (b), collisions events (c), and ionization (d).

\begin{tabular}{|c|c|c|}
\hline PMMA layer thickness & $200 \mathrm{~nm}$ & $770 \mathrm{~nm}$ \\
\hline Material & 950PMMA A4 & 950PMMA A7 \\
\hline $\mathbf{1}^{\text {st }} \mathbf{s t e p}$ & $\begin{array}{c}\text { Deposition: } 1000 \mathrm{rpm} \text { for } 5 \mathrm{~s} \\
\text { Acceleration: } 1500 \mathrm{rpm} / \mathrm{s}\end{array}$ & $\begin{array}{c}\text { Deposition: } 1000 \mathrm{rpm} \text { for } 5 \mathrm{~s} \\
\text { Acceleration: } 1500 \mathrm{rpm} / \mathrm{s}\end{array}$ \\
\hline $2^{\text {nd }} \mathbf{s t e p}$ & $\begin{array}{c}\text { Deposition: } 7000 \mathrm{rpm} \text { for } 45 \mathrm{~s} \\
\text { Acceleration: } 10000 \mathrm{rpm} / \mathrm{s}\end{array}$ & $\begin{array}{c}\text { Deposition: } 2200 \mathrm{rpm} \text { for } 45 \mathrm{~s} \\
\text { Acceleration: } 10000 \mathrm{rpm} / \mathrm{s}\end{array}$ \\
\hline
\end{tabular}

Table S1. Spin-coating procedures for deposition of PMMA layers for the first model samples.

\section{Acknowledgments}

We would like to acknowledge Dr. Agnieszka Telecka for fabricating the bulk PMMA samples. Funding from CellTom, CellTom part-financed by Interreg Deutschland-Danmark with means from the European Regional Development Fund (ERDF). 


\section{References}

[1] D. C. Joy, Helium Ion Microscopy - Principles and Applications, 1st ed. (Springer, New York, 2013).

[2] I. Shorubalko, L. Pillatsch, and I. Utke, in Helium Ion Microscopy, edited by Gregor Hlawacek and Armin Gölzhäuser (Springer, Switzerland, 2016), p. 355-393.

[3] A. Kondyurin and M. Bilek, Ion Beam Treatment of Polymers - Application aspects from medicine to space, 2nd ed. (Elsevier, 2014).

[4] K. Vutova and G. Mladenov, in Lithography, edited by M. Wang (IntechOpen, 2010), p. 319-350.

[5] R. S. Thomaz and R. M.Papaléo, in Radiation Effects in Polymeric Materials edited by V. Kumar, B. Chaudhary, V. Sharma, and V. Verma (Springer Nature Switzerland, 2019), p. 112-137.

[6] M. Haiducu, M. Rahbar, I. G. Foulds, R. W. Johnstone, D. Sameoto, and M. Parameswaran, J. Micromech. Microeng. 18, 115029 (2008).

[7] K. A. Valiev, The Physics of Submicron Lithography, 1st ed. (Springer US, 1992).

[8] A. Licciardello, M. E. Fragalà, G. Foti, G. Compagnini, and O. Puglisi, Nucl. Instr. and Meth. in Phys. Res. B 116, 168 (1996).

[9] F. Schrempel, Y. S. Kim, and W. Witthuhn, Appl. Surf. Sci. 189, 102 (2002).

[10] L. Torrisi, Radiation Effects and Defects in Solids 145, 285 (1998).

[11] Y. Koval, J. Vac. Sci. Technol. B 22, 843 (2004).

[12] A. Telecka, N. K. Mandsberg, T. Li, E. Ludvigsen, S. Ndoni, R. Di Mundo, F. Palumbo, J. Fiutowski, S. Chiriaev, and R. Taboryski, Nanoscale 10, 20652 (2018).

[13] O. Olabisi and K. Adewale, Handbook of Thermoplastics, 2nd ed. (CRC Press, 2015).

[14] R.Kallweita, M. Baur, P. Eichinger, and H. Strack, Nucl. Instr. and Meth. in Phys. Res. B 59-60, 1288 (1991).

[15] D. M. Rück, J. Schulz, and N. Deusch, Nucl. Instr. and Meth. in Phys. Res. B 131, 149 (1997).

[16] H. W. Choi, H. J. Woo, W. Hong, J. K. Kim, S. K. Lee, and C. H. Eum, Appl. Surf. Sci. 169-170, 433 (2001).

[17] S. Unai, N. Puttaraksa, N. Pussadee, K. Singkarat, M. W. Rhodes, H. J. Whitlow, and S. Singkarat, Microelectron. Eng. 102, 18 (2013). 